\title{
DNA methylation profiles of 22 apoptosis-related genes in odontogenic keratocysts before and after marsupialization
}

Karuza Maria Alves Pereira, DDS, MSc, PhD, ${ }^{a}$ Sara Ferreira dos Santos Costa, DDS, MSc, ${ }^{b}$

Núbia Braga Pereira, DDS, MSc, PhD, ${ }^{\mathrm{b}}$ Marina Gonçalves Diniz, DDS, MSc, PhD, ${ }^{\mathrm{b}}$

Wagner Henriques Castro, DDS, MSc, PhD, ${ }^{\mathrm{b}}$ Carolina Cavaliéri Gomes, DDS, MSc, $\mathrm{PhD},{ }^{\mathrm{c}}$ and

Ricardo Santiago Gomez, DDS, MSc, $\mathrm{PhD}^{\mathrm{b}}$

Objective. Odontogenic keratocysts (OKCs) are cystic lesions of the jaw and tend to recur after treatment. Marsupialization is an effective preliminary treatment for large OKCs. This procedure induces epithelial lining changes in association with reduction of $\mathrm{Bcl}-2$ protein expression, but the underlying mechanisms remain unknown. The purpose of our study was to compare the methylation profile of the apoptosis-related genes of OKCs before and after marsupialization.

Study Design. We assessed the methylation percentages of the promoter region of 22 apoptosis-related genes in 13 OKCs, both marsupialized and nonmarsupialized lesions, by using methylation quantitative polymerase chain reaction array. We validated the expression of genes that showed the greatest differences in methylation percentages between the 2 groups.

Results. $L T B R$ and BCLAF1 showed higher DNA methylation percentages in the marsupialized OKCs, but this difference did not affect gene expression $(P>$.05). The other 20 genes showed similar DNA methylation in both OKC groups.

Conclusions. OKCs show a distinct methylation profile after marsupialization, but this is not followed by gene expression alterations. (Oral Surg Oral Med Oral Pathol Oral Radiol 2017;124:483-489)

Odontogenic keratocysts (OKCs) were first described by Philipsen in $1956 .{ }^{1}$ These cysts have a predilection for the posterior region of the mandible and a slight male predilection, and their peak incidence occurs in patients 10 to 30 years of age..$^{1-3}$ Besides occurring sporadically, OKCs may occur in association with nevoid basal cell carcinoma syndrome (Gorlin syndrome). ${ }^{1,4} \mathrm{~A}$ number of studies have focused on different aspects of this lesion in an attempt to explain its biologic behavior. ${ }^{5}$ Mutations in the Patched (PTCH1) tumor suppressor gene were identified as the underlying genetic event in nevoid basal cell carcinoma syndrome, ${ }^{6,7}$ occurring in some sporadic OKCs. ${ }^{8-10}$

The most appropriate management for OKC remains controversial ${ }^{11}$ and may include marginal resection, enucleation with or without peripheral ostectomy, or use of the Carnoy solution, decompression, and marsupialization. ${ }^{12-15}$ The recurrence rate is approximately $30 \%{ }^{16}$ and may be associated with the presence of microscopic budding and epithelial islands in a cystic capsule, poor clinical response to decompression, and in-

Support for this study was provided by Conselho Nacional de Desenvolvimento Científico e Tecnológico (CNPq)/Brazil and Fundação de Amparo à Pesquisa do Estado de Minas Gerais (FAPEMIG)/ Brazil. Gomes CC and Gomez RS are research fellows at CNPq/ Brazil.

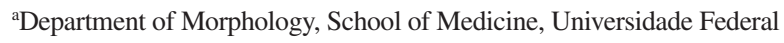
do Ceará, Fortaleza, Brazil.

${ }^{b}$ Department of Oral Surgery and Pathology, School of Dentistry, Universidade Federal de Minas Gerais, Belo Horizonte, Brazil.

cDepartment of Pathology, Biological Sciences Institute, Universidade Federal de Minas Gerais, Belo Horizonte, Brazil.

Received for publication May 6, 2017; returned for revision Jul 13, 2017; accepted for publication Jul 26, 2017.

(C) 2017 Elsevier Inc. All rights reserved.

2212-4403/\$ - see front matter

https://doi.org/10.1016/j.0ooo.2017.07.010 sinuation of the lesion between the dental roots of the remaining tooth during a radiographic examination. ${ }^{3}$

Marsupialization involves converting a cyst into a pouch, and it is an effective preliminary treatment for large OKCs because it is highly successful in decreasing the size of a tumor before definitive surgery. ${ }^{15,17-19}$ With marsupialization, the fibrous capsule of the cyst becomes thicker and easier to enucleate and histologically appears to change and resemble normal oral mucosa. ${ }^{20,21}$ Studies of the mechanism behind the influence of marsupialization on the cystic capsule could provide molecular tools for the treatment of OKCs. Interestingly, apoptosisinvolved protein expression in the cyst epithelium changes after marsupialization. Bcl-2 is an antiapoptotic protein whose prosurvival function was discovered by observing that it promotes hematopoietic cell survival. ${ }^{22} \mathrm{Bcl}-2$ protein expression is strictly limited to the basal layer of the initial biopsy of the OKC lining, but not in the histologic material obtained after marsupialization. ${ }^{20}$ Diniz et al. $^{23}$ compared marsupialized OKCs with primary lesions and noticed an overall reduction in $\mathrm{Bcl}-2$ immunoexpression after marsupialization.

Some studies have focused on the molecular aspects of OKCs, including epigenetic changes. ${ }^{923-28}$ A widely

\section{Statement of Clinical Relevance}

Marsupialization is considered an effective technique for preliminary treatment of large odontogenic keratocysts (OKCs). Some studies have focused on the molecular aspects of OKCs, but whether the impact of epigenetic mechanisms on the biologic changes in OKCs after marsupialization remains unclear. 
known detail is that gene expression can be modulated by phenomena that go further than changes in the DNA sequence (i.e., epigenetic mechanisms). ${ }^{29,30}$ DNA methylation is the most common among epigenetic alterations. DNA methylation is a postreplication modification that is predominantly found in the cytosines of the dinucleotide sequence $\mathrm{CpG}$. This process is associated with gene inactivation during normal development and in a broad range of human diseases. ${ }^{31-33}$ Recently, our group found a hypomethylated profile of BCL2 L11 associated with increased expression of its messenger RNA (mRNA) in ameloblastoma compared with normal tissue, which suggests that the transcription of this apoptosis-related gene is possibly regulated by DNA methylation in the tumor. ${ }^{34}$

The impact of epigenetic mechanisms on the biologic changes in OKCs after marsupialization remains unexplored. The purpose of this study was to compare the methylation profile of 22 apoptosis-related genes between marsupialized OKCs (m-OKCs) and nonmarsupialized OKCs.

\section{MATERIALS AND METHODS Patient recruitment and sample inclusion and processing}

This study was approved by the Research Ethics Committee of the university (COEP-UFMG) (protocol number CAAE 30405514.5.0000.5149), and patients gave informed consent before sample collection. Patients were recruited at the Oral Medicine service at the School of Dentistry/UFMG (Belo Horizonte, Brazil). Patients with Gorlin syndrome were not invited to take part in the study.

Thirteen fresh samples of sporadic OKCs were collected from 13 patients; 9 post-m-OKCs and 4 first biopsy (nonmarsupialized) OKCs were included in this study. The m-OKC and primary OKC samples were obtained from different patients. The age of the patients ranged from 11 to 54 years, and the male/female ratio was 1.16:1. In all cases, the OKCs occurred in the mandible. In the $\mathrm{m}$-OKC group, samples included tissue fragments obtained 8 to 13 months after marsupialization. Histologically, m-OKCs presented moderate to severe inflammatory infiltrate, whereas nonmarsupialized OKCs did not show inflammatory infiltrate. A sample of dental follicles collected from asymptomatic unerupted impacted third molars extracted from healthy individuals was used as the reaction calibrator in transcription validation.

All samples were divided into 3 portions; one was immediately included in Tissue-Tek (Sakura Finetek, Torrance, CA) stored at $-80^{\circ} \mathrm{C}$, another was stored in RNAholder (BioAgency, SP, Brazil) at $-80^{\circ} \mathrm{C}$, and the largest fragment was formalin fixed, paraffin embedded, and submitted for histopathologic analysis to confirm the diagnosis.

\section{DNA methylation analysis}

Each tumor sample was cryosected to guarantee the presence of epithelium. Genomic DNA (gDNA) was extracted using the DNeasy Blood and Tissue Kit (Qiagen Inc., Valencia, CA) according to the manufacturer's protocol. DNA concentration and purity were determined using a spectrophotometer with Nanodrop 2000 (ThermoFisher Scientific, Wilmington, DE), and then samples from each group were combined into pools that contain $1 \mu \mathrm{g}$ of gDNA each.

The methylation status of the promoter region of a panel of 22 apoptosis-related genes was analyzed by using the human methylation signature panel EpiTect Methyl II PCR Array System: EAHS-121 Z (Qiagen, Germantown, MD). The genes included in this panel are listed in Table I. This method is based on the quantitative detection of remaining target DNA molecules after treatment with methylation-sensitive and methylation-dependent restriction enzymes that digest unmethylated and methylated DNA, respectively. The restriction digestions were performed using the EpiTect Methyl II DNA Restriction Kit (Qiagen, Chatsworth, CA) according to the manufacturer's instructions. Four digestion reactions, namely, noenzyme mock (Mo), methylation-sensitive (Ms), methylation-dependent (Md), and methylation-sensitive plus methylation-dependent double (Msd) were set up. The quantitative polymerase chain reaction array was performed in a StepOne Plus Real-Time PCR System (Applied Biosystems, Foster City, CA). Data outputs representing DNA methylation levels were determined and analyzed by using EpiTect Methyl DNA PCR Data Analysis (Qiagen, Chatsworth, CA).

\section{mRNA transcription analysis}

The genes that showed the most striking methylation profile differences among the OKC groups were selected for the transcription analysis by reverse transcription quantitative polymerase chain reaction. Three OKC samples were not included in the mRNA transcription analysis because of the limited amount of available fresh tissue for RNA extraction. Therefore, we used all the available samples that comprised $6 \mathrm{~m}$-OKCs and 4 nonmarsupialized OKCs. Total RNA was extracted from $50 \mathrm{mg}$ to $100 \mathrm{mg}$ of the frozen sample by using TRIzol Reagent (Ambion, Foster City, CA) according to the manufacturer's specifications. Total RNA was treated with DNAse I (Invitrogen Life Technologies, Carlsbad, CA) to avoid gDNA contamination. Reverse transcription from $1 \mu \mathrm{g}$ of treated RNA to complementary DNA was performed using the SuperScript III First-Strand-Synthesis System (Invitrogen, Carlsbad, CA).

Primers for $B C L A F 1$ and $L T B R$ complementary DNA were designed using the Primer Express software; LTBR, forward: 5' GAGATGTCAGGAACCATGCTGAT 3' and reverse: 5' GGTGGCAAGGAGCAGAAAGA3' 
Table I. DNA methylation levels in the 22 genes included in the methylation PCR array in the 2 odontogenic keratocysts $(\mathrm{OKC})$ groups

\begin{tabular}{lrccc}
\hline Genes & OKC $(M)$ & OKC $(U N)$ & $m-O K C(M)$ & $m-O K C(U N)$ \\
\hline APAF1 & $0.58 \%$ & $99.42 \%$ & $0.03 \%$ & $99.97 \%$ \\
BAD & $0.36 \%$ & $99.64 \%$ & $0.09 \%$ & $99.91 \%$ \\
BAX & $0.97 \%$ & $99.03 \%$ & $0.56 \%$ & $99.44 \%$ \\
BCL2 L11 & $66.31 \%$ & $33.69 \%$ & $66.68 \%$ & $33.32 \%$ \\
BCLAF1 & $\mathbf{1 . 1 6 \%}$ & $98.84 \%$ & $\mathbf{5 3 . 6 1 \%}$ & $46.39 \%$ \\
BID & $0.06 \%$ & $99.94 \%$ & $0.10 \%$ & $99.90 \%$ \\
BIK & $0.40 \%$ & $99.60 \%$ & $0.16 \%$ & $99.84 \%$ \\
BIRC2 & $1.49 \%$ & $98.51 \%$ & $0.28 \%$ & $99.72 \%$ \\
BNIP3 & $0.93 \%$ & $99.07 \%$ & $0.14 \%$ & $99.86 \%$ \\
CASP3 & $1.27 \%$ & $98.73 \%$ & $0.67 \%$ & $99.33 \%$ \\
CASP9 & $3,10 \%$ & $96.90 \%$ & $2.93 \%$ & $97.07 \%$ \\
CIDEB & $2.67 \%$ & $97.33 \%$ & $1.30 \%$ & $98.70 \%$ \\
CRADD & $5.12 \%$ & $94.88 \%$ & $2.35 \%$ & $97.65 \%$ \\
DAPK1 & $0.52 \%$ & $99.48 \%$ & $0.44 \%$ & $99.56 \%$ \\
DFFA & $1.85 \%$ & $98.15 \%$ & $0.79 \%$ & $99.21 \%$ \\
FADD & $0.30 \%$ & $99.70 \%$ & $0.10 \%$ & $99.90 \%$ \\
GADD45 & $0.09 \%$ & $99.91 \%$ & $0.38 \%$ & $99.62 \%$ \\
HRK & $0.05 \%$ & $99.95 \%$ & $0.21 \%$ & $99.79 \%$ \\
LTBR & $\mathbf{1 1 . 0 9 \%}$ & $88.91 \%$ & $\mathbf{5 7 . 0 5 \%}$ & $42.95 \%$ \\
TNFRSF21 & $1.09 \%$ & $98.91 \%$ & $0.32 \%$ & $99.68 \%$ \\
TNFRSF25 & $86.10 \%$ & $13.90 \%$ & $71.63 \%$ & $28.37 \%$ \\
TP53 & $2.65 \%$ & $97.35 \%$ & $0.37 \%$ & $99.63 \%$ \\
\hline
\end{tabular}

$M$, methylated DNA; $P C R$, polymerase chain reaction; $U N$, unmethylated DNA.

DNA methylation levels (\%) in marsupialized OKCs (m-OKCs) and nonmarsupialized OKCs.

* LTBR and BCLAF1 were the 2 genes whose methylation percentages showed striking differences between m-OKCs and OKCs. All the other genes showed similar methylation percentage status in the 2 groups.

(69 bp-amplicon); and for BCLAF1 forward: 5'GCG GTTCACTTCGTATCAGAAAG3' and reverse: 5' GAGATGTCAATTCTCCTGTGTATTTCA 3' (84 bpamplicon). Some endogenous control genes were tested, and $28 \mathrm{~S}$ was chosen to normalize all reactions. All reactions were performed in duplicate in a StepOne Plus Real-time PCR System using the PowerUp SYBRgreen fluorescence quantification system (Applied Biosystems, Austin, TX). One sample of dental follicle was used as the reaction calibrator. Analysis of relative gene expression was performed by using the $2^{-\Delta \Delta C T}$ method. The data were presented as the relative quantity of targets normalized to endogenous $28 \mathrm{~S}$ and relative to a calibrator sample.

\section{Statistical analysis}

Statistical analysis was performed using GraphPad Prism 5.0 (GraphPad Software, Inc., La Jolla, CA). The MannWhitney $\mathrm{U}$ test was used for comparison among groups. $P$ values $<.05$ were considered statistically significant.

\section{RESULTS}

\section{DNA methylation analyses}

$L T B R$ and BCLAF1 showed different DNA methylation patterns between the m-OKCs and the nonmarsupialized OKCs. The methylation results are shown in Table I and Figure 1. LTBR methylation frequency in the m-OKC group $(57.1 \%)$ was higher than that in the OKC group $(11.1 \%)$. BCLAF1 was also more highly methylated in the m-OKC (53.6\%) group compared with the OKC group $(1.2 \%)$ (Table I; Figure 1).

The methylation percentage of the other gene promoters that were studied was low and similar between the 2 OKC groups (Table I; Figure 1).

\section{Gene expression analyses}

No statistically significant difference was observed in the transcription levels of the $L T B R$ and BCLAF1 genes between the marsupialized and nonmarsupialized OKC lesions $(P>.05)$. These results are shown in Figure 2.

\section{DISCUSSION}

Epigenetic changes are nongenetic alterations that can affect regulation of gene expression without changing DNA sequence. ${ }^{31,32}$ DNA methylation is the most extensively studied epigenetic phenomenon, and abnormalities of DNA methylation patterns are observed in different diseases, including odontogenic tumors ${ }^{34}$ and cancers. ${ }^{35}$ These abnormalities include promoter $\mathrm{CpG}$ island DNA hypermethylation, which is related to transcriptional silencing of genes, such as tumor suppressor genes. ${ }^{30,36}$ DNA hypomethylation has also been found in many types of cancers, but its biologic significance is not understood. ${ }^{37,38}$ Few published data exist on the 

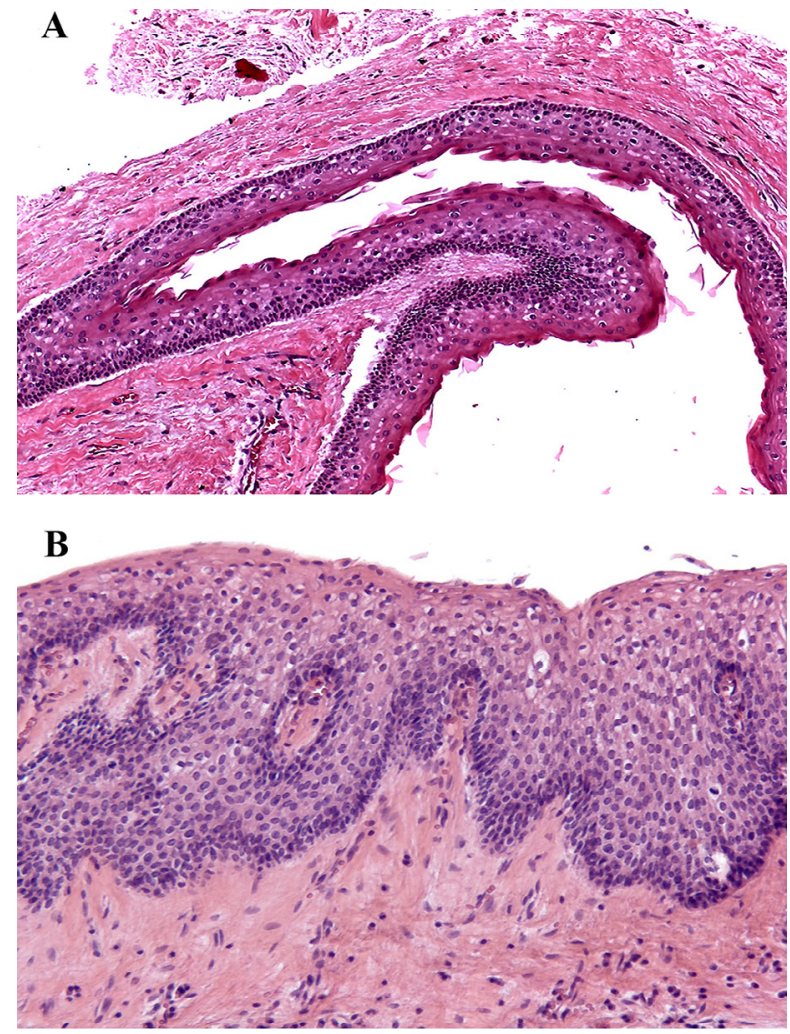

$\mathrm{C}_{\text {okC }}$ m-0KC

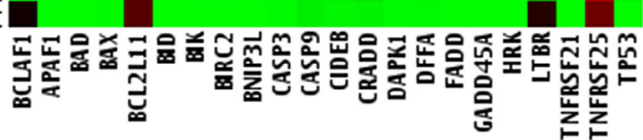
\% $50 \%$ $100 \%$

Fig. 1. Histopathologic aspects of odontogenic keratocysts (OKCs) before and after marsupialization and the heat map of methylation results. A, Histopathologic presentation of the OKC before marsupialization showing the fibrous capsule lined by a uniformly thickened parakeratinized epithelium with palisaded basal cell layer. B, After marsupialization, some of the typical features of the OKC are lost. C, Heat map showing DNA methylation profiles of apoptosis-related genes in the marsupialized odontogenic keratocyst (m-OKC) group and the nonmarsupialized OKC group. Light green (left on the \% scale) indicates a less methylated percentage, and red (right on the \% scale) indicates a higher methylation percentage (A and B, hematoxylin and eosin staining, original magnification $\times 100$ ).

epigenetic changes in OKCs. DNA methylation depends on the addition of methyl groups to cytosine nucleotides in specific areas of the gene by DNA methyltransferases enzymes. Increased expression of this enzyme was found in OKCs. ${ }^{28}$ Moreover, methylation of the $P 21$ gene was reported in OKCs, but protein expression analysis was not performed. ${ }^{27}$ The promoter of PTCHl gene in OKCs was not hypermethylated. ${ }^{10}$ Anal- ysis of global LINE-1 (long interspersed nuclear elementI) methylation profile showed differences between OKCs and ameloblastomas. ${ }^{39}$

Diverse cellular functions, including regulation of inflammatory gene expression, DNA repair, and cell proliferation, are regulated by changes in DNA methylation and post-translational modifications of histones. ${ }^{40}$ DNA methylation may silence gene expression, including expression of apoptosis-related genes ${ }^{41}$ Apoptosis (programmed cell death) is crucial to the efficiency of cellular homeostasis. Disruption of the balance between cell proliferation and cell death as a result of modifications in the apoptotic pathway leads to various human diseases, including cancer. ${ }^{42}$ With regard to apoptotic proteins in OKCs, a number of studies have observed immunoexpression of apoptosis-related factors in the epithelial lining of this lesion. ${ }^{20,23,43-48}$ Expression of the antiapoptotic protein $\mathrm{Bcl}-2$ has been described in OKCs. ${ }^{23,48}$ However, the relevance of this finding has not been discussed in detail. ${ }^{23}$ Cells use a variety of molecular mechanisms, such as epigenetic alterations in the apoptotic genes and oncogenic mutations, to acquire resistance to apoptosis. ${ }^{42,48-50}$

To our knowledge, this study is the first to describe methylation in apoptosis-related genes in OKCs. Our results showed higher methylation percentages at the genes BCLAF1 and LTBR in marsupialized lesions compared with nonmarsupialized samples. These genes are inducers of apoptosis, and their overexpression has been shown in different tumor types. BCLAF1 (bcl-2associated transcription factor 1 ), which is a proapoptotic member of the Bcl-2 family, interacts with antiapoptotic members and can induce apoptosis and autophagy. ${ }^{51,52}$ Increased $B C L A F 1$ expression was reported in rectal cancer, ${ }^{52}$ and upregulation of $B C L A F 1$ was found in patients with recurrent esophageal squamous cell carcinoma. ${ }^{53}$ LTBR (lymphotoxin-beta receptor) is a member of the tumor necrosis factor (TNF) receptor family, and its ligand is TNFSF14/LIGHT. The TNFSF14/ LTBR signaling pathway induces cell death via caspasedependent and caspase-independent pathways. ${ }^{54}$ Various studies have suggested the involvement of the LTBR signaling pathway in malignant tumors, ${ }^{55}$ such as nonHodgkin lymphoma,${ }^{56}$ hepatocellular carcinoma, ${ }^{57}$ and prostate cancer. ${ }^{58}$ An agonistic anti-LTBR antibody inhibited tumor growth in xenograft models of colon carcinoma, suggesting a novel approach to the treatment of this cancer..$^{59}$

Considering that we found hypermethylation of both $B C L A F 1$ and $L T B R$ in $\mathrm{m}-\mathrm{OKCs}$, we would expect them to be underexpressed in the lesions. However, despite the differences in the methylation patterns in OKC lesions before and after the marsupialization, no change in gene expression was found. The relationship between methylation and gene expression is a complex 

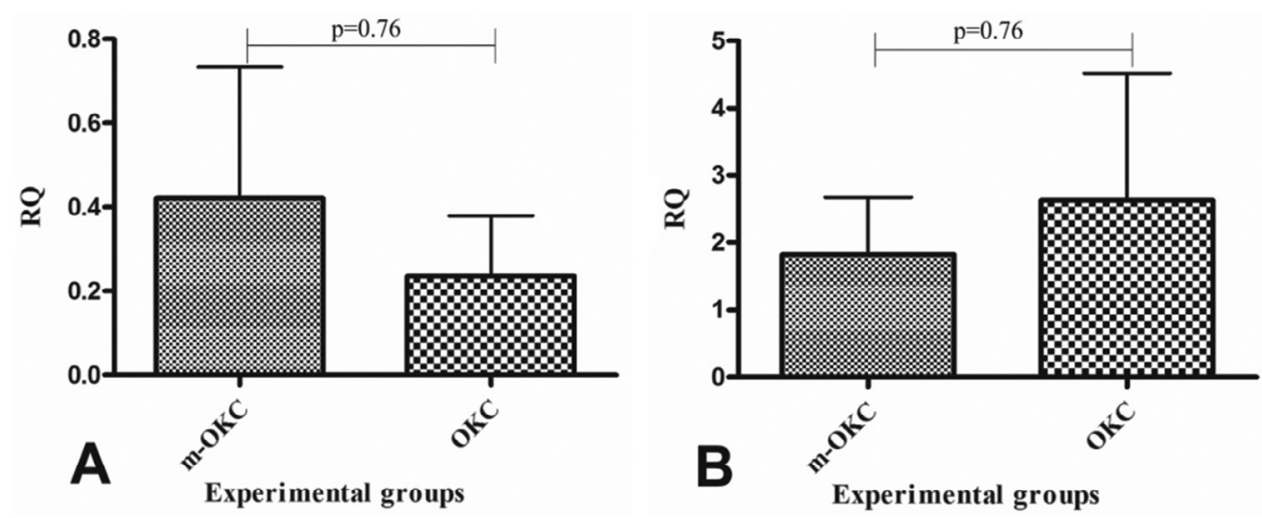

Fig. 2. $L T B R$ and BCLAF1 gene expression in marsupialized odontogenic keratocysts (m-OKCs) and OKCs. A, LTBR gene expression in $\mathrm{m}-\mathrm{OKCs}$ and nonmarsupialized OKCs. B, BCLAF1 gene expression in $\mathrm{m}-\mathrm{OKCs}$ and nonmarsupialized OKCs. $L T B R$ and $B C L A F 1$ gene expression in m-OKCs was not statistically different compared with that in OKCs $(P=.76) \mathrm{Mann}-\mathrm{Whitney} \mathrm{U}$ test. $R Q$, Relative quantification.

phenomenon, ${ }^{30,60,61}$ which can be influenced by many factors, including the presence of inflammation ${ }^{48}$ and tumor heterogeneity. ${ }^{62,63}$ Therefore, the inflammatory infiltrate could have contributed to the epigenetic changes in m-OKCs. This hypothesis is supported by a previous study by Sreedhar et al., which showed that inflamed OKCs exhibit altered expression of factors related to cellular proliferation and apoptosis compared with noninflamed OKCs. ${ }^{48}$ Furthermore, even well-described methylation events, such as promoter $\mathrm{CpG}$ methylation, do not always result in gene silencing, especially when these promoters are characterized by a low $\mathrm{CpG}$ density. ${ }^{30}$

The low number of samples is one limitation of our study. Another limitation was that samples of cysts before and after marsupialization were obtained from different patients because the amount of tissue available in each biopsy was not sufficient to perform all the experiments.

\section{CONCLUSIONS}

OKCs show a distinct methylation profile after marsupialization, but this is not followed by gene expression alterations.

\section{REFERENCES}

1. Speight P, Devilliers P, Li T-J, Odell WE, Wright JM. Odontogenic keratocyst. In: El-Naggar E.K., Chan J.K.C., Grandis J.R., Takata T., Slootweg P.J., eds. World Health Organization Classification of Tumours. Pathology and Genetics. Head and Neck Tumours. Lyon, France: IARC Press; 2017:235-236.

2. Jones AV, Craig GT, Franklin CD. Range and demographics of odontogenic cysts diagnosed in a UK population over a 30-year period. J Oral Pathol Med. 2006;35:500-507.

3. Cunha JF, Gomes CC, Mesquita RA, Goulart EMA, Castro WA, Gomez RS. Clinicopathologic features associated with recurrence of the odontogenic keratocyst: a cohort retrospective analysis. Oral Surg Oral Med Oral Pathol Oral Radiol. 2016;121:629-635.
4. Gorlin RJ, Goltz RW. Multiple nevoid basal-cell epithelioma, jaw cysts and bifid rib. A syndrome. N Engl J Med. 1960;5: 908-912.

5. Gomes CC, Diniz MG, Gomez RS. Review of the molecular pathogenesis of the odontogenic keratocyst. Oral Oncol. 2009; 45:1011-1014.

6. Hahn H, Christiansen J, Wicking C, et al. A mammalian patched homolog is expressed in target tissues of sonic hedgehog and maps to a region associated with developmental abnormalities. J Biol Chem. 1996;271:12125-12128.

7. Johnson RL1, Rothman AL, Xie J, et al. Human homolog of Patched, a candidate gene for the basal cell nevus syndrome. Science. 1996;272:1668-1671.

8. Barreto DC, Gomez RS, Bale AE, Boson WL, De Marco L. PTCH gene mutations in odontogenic keratocysts. J Dent Res. 2000;79:1418-1422.

9. Shear M. The aggressive nature of the odontogenic keratocyst: is it a benign cystic neoplasm? Part 2. Proliferation and genetic studies. Oral Oncol. 2002;38:323-331.

10. Pan S, Dong Q, Sun LS, Li TJ. Mechanisms of inactivation of PTCH1 gene in nevoid basal cell carcinoma syndrome: modification of the two-hit hypothesis. Clin Cancer Res. 2010;16:442-450.

11. Pogrel MA. The keratocystic odontogenic tumour (KCOT) —an odyssey. Int J Oral Maxillofac Surg. 2015;44:1565-1568.

12. Pogrel MA. Decompression and marsupialization as a treatment for the odontogenic keratocyst. Oral Maxillofac Surg Clin North Am. 2003;15:415-427.

13. Madras J, Lapointe H. Keratocystic odontogenic tumour: reclassification of the odontogenic keratocyst from cyst to tumour. J Can Dent Assoc. 2008;74:165-165h.

14. Johnson NR, Bastone MD, Savage NW. Management and recurrence of keratocystic odontogenic tumor: a systematic review. Oral Surg Oral Med Oral Pathol Oral Radiol. 2013; 116:e271-e276.

15. Wushou A, Zhao YZ, Shao ZM. Marsupialization is the optimal treatment approach for keratocystic odontogenic tumour. $J$ Craniomaxillofac Surg. 2014;42:1540-1544.

16. Chrcanovic BR, Gomez RS. Recurrence probability for keratocystic odontogenic tumors: an analysis of 6427 cases. J Craniomaxillofac Surg. 2017;45:244-251.

17. Nakamura N, Mitsuyasu T, Mitsuyasu Y, Taketomi T, Higuchi Y, Ohishi M. Marsupialization for odontogenic keratocysts: 
long-term follow-up analysis of the effects and changes in growth characteristics. Oral Surg Oral Med Oral Pathol Oral Radiol Endod. 2002;94:543-553.

18. Bell RB, Dierks EJ. Treatment options for the recurrent odontogenic keratocyst. Oral Maxillofac Surg Clin North Am. 2003;15:429-446.

19. Pogrel MA. Treatment of keratocysts: the case for decompression and marsupialization. J Oral Maxillofac Surg. 2005;63: 1667-1673.

20. Pogrel MA, Jordan RCK. Marsupialization as a definitive treatment for the odontogenic keratocyst. J Oral Maxillofac Surg. 2004;62:651-655. discussion 655-656.

21. Telles DC, Castro WH, Gomez RS, Souto GR, Mesquita RA. Morphometric evaluation of keratocystic odontogenic tumor before and after marsupialization. Braz Oral Res. 2013;27: 496-502.

22. Vaux DL, Cory S, Adams JM. Bcl-2 gene promotes haemopoietic cell survival and cooperates with c-myc to immortalize pre-B cells. Nature. 1988;335:440-442.

23. Diniz MG, Gomes CC, de Castro WH, et al. miR-15 a/16-1 influences BCL2 expression in keratocystic odontogenic tumors. Cell Oncol (Dordr). 2012;35:285-291

24. Agaram NP, Collins B, Barnes L, et al. Molecular analysis to demonstrate that odontogenic keratocysts are neoplastic. Arch Pathol Lab Med. 2004;128:313-317.

25. Sun LS, Li XF, Li TJ. PTCH1 and SMO gene alterations in keratocystic odontogenic tumors. J Dent Res. 2008;87:575579 .

26. Diniz MG, Borges ER, Guimarães ASR, et al. PTCH1 isoforms in odontogenic keratocysts. Oral Oncol. 2009;45: 291-295.

27. Moreira PR, Guimarães MM, Guimarães AL, et al. Methylation of P16, 027, RB1 and P53 genes in odontogenic keratocysts. J Oral Pathol Med. 2009;38:99-103.

28. Gomes CC, Brito JAR, Andrade CIA, Gomez RS. DNA methyltransferase expression in odontogenic cysts and tumours. Oncol Lett. 2010;1:143-146.

29. Goldberg AD, Allis CD, Bernstein E. Epigenetics: a landscape takes shape. Cell. 2007;128:635-638.

30. Spruijt CG, Vermeulen M. DNA methylation: old dog, new tricks? Nat Struct Mol Biol. 2014;21:949-954.

31. Jones PA, Laird PW. Cancer epigenetics comes of age. Nat Genet. 1999:21:163-167.

32. Jaenisch R, Bird A. Epigenetic regulation of gene expression: how the genome integrates intrinsic and environmental signals. Nat Genet. 2003;33:245-254.

33. Jones PA, Issa JP, Baylin S. Targeting the cancer epigenome for therapy. Nat Rev Genet. 2016;17:630-641.

34. Costa SFS, Pereira NB, Pereira KMA, et al. DNA methylation pattern of apoptosis-related genes in ameloblastomas. Oral Dis. 2017:23:779-783

35. You JS, Jones PA. Cancer genetics and epigenetics: two sides of the same coin? Cancer Cell. 2012;22:9-20.

36. Esteller M. Epigenetic gene silencing in cancer: the DNA hypermethylome. Hum Mol Genet. 2007;16:50-59.

37. Wilson A, Power B, Molloy P. DNA hypomethylation and human diseases. Biochim Biophys Acta. 2007;1775: 138-162.

38. Ehrlich M. DNA hypomethylation in cancer cells. Epigenomics. 2009;1:239-259.

39. Kitkumthorn N, Mutirangura A. LINE-1 methylation difference between ameloblastoma and keratocystic odontogenic tumor. Oral Dis. 2010;16:286-291.

40. Adcock IM, Tsaprouni L, Bhavsar P, Ito K. Epigenetic regulation of airway inflammation. Curr Opin Immunol. 2007;19:694-700.
41. Shridhar K, Walia KG, Aggarwal A, et al. DNA methylation markers for oral pre-cancer progression: a critical review. Oral Oncol. 2016;53:1-9.

42. Hervouet E, Cheray M, Vallette FM, Cartron PF. DNA methylation and apoptosis resistance in cancer cells. Cell. 2013;293:545-573.

43. Kimi K, Kumamoto H, Ooya K, Motegi K. Analysis of apoptosisrelated factors and apoptotic cells in lining epithelium of odontogenic keratocysts. J Oral Pathol Med. 2000;5:35-40.

44. Kimi K, Kumamoto H, Ooya K, Moteg K. Immunohistochemical analysis of cell-cycle- and apoptosis-related factors in lining epithelium of odontogenic keratocysts. J Oral Pathol Med. 2001;30:434-442

45. Kichi E, Enokiya Y, Muramatsu T, et al. Cell proliferation, apoptosis and apoptosis-related factors in odontogenic keratocysts and in dentigerous cysts. J Oral Pathol Med. 2005;34:280-286.

46. Metgud R, Gupta K. Expression of cell cycle and apoptosis-related proteins in ameloblastoma and keratocystic odontogenic tumor. Ann Diagn Pathol. 2013;17:518-521.

47. Razavi SM, Torabinia N, Mohajeri MR, Shahriyary S, Ghalegolab S, Nouri S. Expression of Bcl-2 and epithelial growth factor receptor proteins in keratocystic odontogenic tumor in comparison with dentigerous cyst and ameloblastoma. Dent Res J (Isfahan). 2015:12:342-347

48. Sreedhar G, Raju MV, Metta KK, Manjunath SM, Shetty S, Agarwal RK. Immunohistochemical analysis of factors related to apoptosis and cellular proliferation in relation to inflammation in dentigerous and odontogenic keratocyst. J Nat Sci Biol Med. 2014:5:112-115.

49. Igney F, Krammer P. Death and anti-death: tumour resistance to apoptosis. Nat Rev Cancer. 2002;2:277-288.

50. Delbridge A, Valente L, Strasser A. The role of the apoptotic machinery in tumor suppression. Cold Spring Harb Perspect Biol. 2012;4:a008789.

51. Kasof G, Goyal L, White E. Btf, a novel death-promoting transcriptional repressor that interacts with Bcl-2-related proteins. Mol Cell Biol. 1999;19:4390-4404.

52. Brown G, Cash B, Alnabulsi A, Samuel LM, Murray GI. The expression and prognostic significance of bcl-2-associated transcription factor 1 in rectal cancer following neoadjuvant therapy. Histopathology. 2016;68:556-566.

53. Chen Y, Wang Y, Song H, et al. Expression profile of apoptosisrelated genes potentially explains early recurrence after definitive chemoradiation in esophageal squamous cell carcinoma. Tumour Biol. 2014:35:4339-4346.

54. You R, Chen M, Wang H, Chou YC, Lin CH, Hsieh SL. Inhibition of lymphotoxin-beta receptor-mediated cell death by survivinDeltaEx3. Cancer Res. 2006;66:3051-3061.

55. Fernandes MT, Dejardin E, Santos N. Context-dependent roles for lymphotoxin- $\beta$ receptor signaling in cancer development. Biochim Biophys Acta. 2016;1865:204-219.

56. Warzocha K, Ribeiro P, Renard N, et al. Expression of genes coding for the tumor necrosis factor and lymphotoxin ligandreceptor system in non-Hodgkin's lymphomas. Cancer Immunol Immunother. 2000;49:469-475.

57. Haybaeck J, Zeller N, Wolf M, et al. A lymphotoxin-driven pathway to hepatocellular carcinoma. Cancer Cell. 2009;16:295308.

58. Wolf M, Seleznik G, Zeller N, et al. The unexpected role of lymphotoxin $\beta$ receptor signaling in carcinogenesis: from lymphoid tissue formation to liver and prostate cancer development. Oncogene. 2010;29:5006-5018.

59. Lukashev M, Lepage D, Wilson C, et al. Targeting the lymphotoxin-beta receptor with agonist antibodies as a potential cancer therapy. Cancer Res. 2006;66:9617-9624. 
60. Campos K, Franscisconi CA, Okehie V, et al. FOXP3 DNA methylation levels as a potential biomarker in the development of periapical lesions. J Endod. 2015;41:212-218.

61. Schübeler D. Function and information content of DNA methylation. Nature. 2015;517:321-326.

62. Gomes CC, Fonseca-Silva T, Galvão CF, Friedman E, De Marco L, Gomez RS. Inter- and intra-lesional molecular heterogeneity of oral leukoplakia. Oral Oncol. 2015;51:178181.

63. Gomes CC, Galvão CF, do Carmo AC, Pereira NB, Gomez RS. Intratumor molecular heterogeneity in pleomorphic adenoma of the salivary glands. Oral Surg Oral Med Oral Pathol Oral Radiol. 2016;121:158-163.

Reprint requests:

Karuza Maria Alves Pereira, DDS, MSc, $\mathrm{PhD}$

Department of Morphology, School of Medicine

Universidade Federal do Ceará

Rua Delmiro de Farias s/n - Rodolfo Teófilo

CEP 60416-030, Fortaleza, CE

Brazil

Karuzaalves@yahoo.com.br 